\title{
A study on the effects of remote working on quality of services: A SERVQUAL survey on central office of Tehran municipality
}

\author{
Hassan Darvish $^{\mathrm{a}}$ and Fariba Hedayati Shirsavar ${ }^{\mathrm{b}^{*}}$
}

\author{
${ }^{a}$ Assistant professor, Department of Economic ,Management and Accounting, Payame Noor University 19395-4697,Tehran, Iran \\ ${ }^{b}$ Department of Management, Tehran Branch, Payame Noor University, Tehran, Iran

\section{H R O N I C L E} \\ A B S T R A C T
}

Article history:

Received January 20, 2013

Received in revised format

12 May 2013

Accepted May 182013

Available online

May 192013

Keywords:

SERVQUAL

Municipality of Tehran

Remote working

\begin{abstract}
During the past few years, there have been tremendous efforts on developing remote working among women in an attempt to help females take care of their family related responsibilities. In this paper, we study the impact of remote working on quality of services in central office of Tehran municipality of Iran. The proposed study designs a standard questionnaire to survey remote working and using an existing standard SERVQUAL questionnaire measure the level of quality of work because of remote working. The survey indicates that women who participated in remote working program were satisfied from this program in terms of personal, social as well as organizational productivity. Remote workers were highly satisfied from financial advantage of this program. Managers were, however, highly satisfied from the results of their female's remote working. In our survey, remote contract workers were more satisfied than remote formal workers were. The surveyed people believed organizational structure was the most important challenge for remote working followed by economical, personal and social issues. The results of SERVQUAL also indicate there were some meaningful relationship between remote working and quality of work.
\end{abstract}

(C) 2013 Growing Science Ltd. All rights reserved.

\section{Introduction}

During the past few years, there have been tremendous efforts on developing remote working among women in an attempt to help females take care of their family related responsibilities (Bird, 1986; Dujardin et al., 2012). According to Dowling (2012), remote working and flexible hours for employees may help to keep businesses productive but this should not be at the cost of the firm's information security protection. Hart (2009) remote working is a kind of managing the balancing act between network access and data security. Tromp and Blomme (2012) discussed the effect of effort cost, job control and work-home arrangements on negative work-home interference in the hospitality industry. The study concerned higher educated employees who had been graduated from a business university. They reported working overtime, work-home arrangements and autonomy were 
significantly associated with negative work-home interference giving proof to the Effort-Recovery model. In addition, employees who worked in the hospitality industry stated significantly more working overtime and less being positive about the work-home arrangements while these were the most important predictors of negative work-home interference. The results gave directions to what HRM policies organizations should paid attention to, to minimize negative work-home interference and its negative consequences among their employees.

Perugia et al. (2011) presented a model and an algorithm for the design of a home-to-work bus service in a metropolitan area. They analyzed a home-to-work bus service for a large research center located in Rome, Italy and the case study provided a benchmark for the algorithmic results, and showed the practical relevance of the proposed methodology.

Ghafur (2002) examined the use of space in home-based work in slums in Bangladesh to realize urban poor women's involvement in relation to men. While women's access and implementation of spaces were restricted by social practice, their income generation initiatives were further influenced by settlement specific factors. As a consequence, women's direct and indirect dependence on men emerges. This male-female involvement took place not only to mutually share the activities of homebased work for operational conveniences but also to supplement a given household's effort to pool income for its survival on a daily basis.

In this paper, we study the impact of remote working on quality of services in central office of Tehran municipality of Iran. The organization of this paper first presents details of the proposed study in section 2 . Section 3 presents details of our findings and finally concluding remarks are given in the last to summarize the contribution of the paper.

\section{The proposed study}

In this paper, we investigate the impact of remote working on quality of services in central office of Tehran municipality of Iran. The proposed study designs a standard questionnaire to survey remote working and using an existing standard SERVQUAL questionnaire measure the level of quality of work because of remote working. All questions were designed based in Likert scale from 1 to 5 .

The sample size of this survey is determined based on Morgan table as 160 . In this survey, we have selected the population into five regions of north, center, south, west and east. The survey detected 170 employed women and 36 managers. Cronbach alpha for the first questionnaire was estimated to 0.85. In addition, Cronbach alpha for SERVQUAL questionnaire are summarized in Table 1 as follows,

Table 1

The summary of SERVQUAL questionnaire (Overall Cronbach $=0.85$ )

\begin{tabular}{lrrrrc}
\hline & Guarantee & \multicolumn{1}{c}{ Credit } & Tangible & Empathy & Responsive \\
\hline Perception & 0.74 & 0.81 & 0.87 & 0.70 & 0.80 \\
Expectation & 0.77 & 0.82 & 0.85 & 0.72 & 0.76 \\
\hline
\end{tabular}

\section{The results}

In this section, we present details of our survey on testing different hypotheses of this survey.

\subsection{The first hypothesis}

The first hypothesis of this survey investigates whether female workers are satisfied from distance working or not. Table 2 summarizes the results of our survey. 
Table 2

The summary of testing the first hypothesis

\begin{tabular}{lccccccc}
\hline Satisfaction from & Mean & Std dev. & Min & Max & t-value & df & P-value \\
\hline Personal and social & 2.49 & 0.52 & 1.31 & 4.23 & 10.63 & 169 & 0.001 \\
Economical & 4.13 & 0.52 & 2.40 & 5 & 35.17 & 169 & 0.001 \\
Organizational efficiency & 2.46 & 0.43 & 1.46 & 3.46 & 10.63 & 169 & 0.001 \\
Remote working & 3.36 & 0.48 & 1.36 & 4.69 & 6.16 & 169 & 0.001 \\
\hline
\end{tabular}

According to the results of Table 2, women are satisfied in terms of personal, economical as well as organizational efficiency when the level of significance is one percent.

\subsection{The second hypothesis}

The second hypothesis of this survey examines whether management team are satisfied from their females' distance working or not. Table 3 shows the results of our survey.

Table 3

The summary of testing the second hypothesis

\begin{tabular}{lccccccc}
\hline Component & Mean & Std dev. & Min & Max & t-value & df & P-value \\
\hline $\begin{array}{l}\text { Management satisfaction from } \\
\text { their females' remote working }\end{array}$ & 4.31 & 0.73 & 1.11 & 4.75 & 5.21 & 35 & 0.011 \\
\hline
\end{tabular}

Based on the results of Table 3, management team is satisfied from their females' remote working when the level of significance is one percent.

\subsection{The third hypothesis: Remote working and employees’ personal characteristics}

In this section, we present details of our survey on relationship between remote workers' personal characteristics and their satisfactions.

\subsubsection{Marital status}

We first looks into find out whether there is any difference between the levels of job satisfaction among female remote workers in terms of their marital status. Table 4 summarizes the results of our survey.

\section{Table 4}

The summary of testing the third hypothesis

\begin{tabular}{lccccccc}
\hline Marital status & Mean & Std dev. & Min & Max & t-value & df & P-value \\
\hline Single & 2.31 & 0.73 & 1.11 & 4.75 & 5.21 & 168 & 0.001 \\
Married & 4.13 & 0.63 & 1.24 & 4.14 & & & \\
\hline
\end{tabular}

According to the results of Table 4, there is a meaningful difference between two groups of singles and married employees when the level of significance is one percent. Our further investigation indicates married women were more satisfied from distance working than single ones.

\subsubsection{Employment status}

We also try to detect whether there is any difference between the level of job satisfaction among female remote workers in terms of their job status, e.g. contract or permanent employee status. Table 5 summarizes the results of our survey. 


\section{Table 5}

The summary of testing the effects of employment status

\begin{tabular}{lccccccc}
\hline Employment status & Mean & Std dev. & Min & Max & t-value & df & P-value \\
\hline Permanent & 2.31 & 0.33 & 1.81 & 3.56 & 4.29 & 168 & 0.001 \\
Contract & 4.13 & 0.23 & 2.24 & 4.29 & & & \\
\hline
\end{tabular}

Based on the results of Table 5, there is a meaningful difference between two groups of permanent and contract employees when the level of significance is one percent. Our further investigation indicates contract women were more satisfied from distance working than permanent ones.

\subsubsection{Educational background status}

Finally, we survey to find out whether there is any difference between the levels of job satisfaction among female remote workers in terms of their educational backgrounds. Table 7 summarizes the results of our survey.

Table 7

The summary of ANOVA test on the effects of educational background

\begin{tabular}{lccccc}
\hline Groups & Sum of squares & df & Mean of squares & F & P-value \\
\hline Between groups & 289 & 4 & 72.25 & 10.67 & 0.001 \\
Inside groups & 1123 & 166 & 6.77 & & \\
\hline
\end{tabular}

Based on the results of Table 7, there is a meaningful difference among women with different educational backgrounds.

\subsection{The fourth hypothesis}

The other is to find out important factors influencing remote working among women. We have used Chi-Square to examine the effects of four factors including structural organization, economical factors, personal issues and social factors. Table 8 shows details of our survey.

\section{Table 8}

The results of Chi-Square test on the effects of various factors

\begin{tabular}{lllllll}
\hline Problem & $\begin{array}{l}\text { Organizational } \\
\text { factors }\end{array}$ & $\begin{array}{l}\text { Economic } \\
\text { factors }\end{array}$ & $\begin{array}{l}\text { Personal } \\
\text { factors }\end{array}$ & $\begin{array}{l}\text { Social } \\
\text { factors }\end{array}$ & Chi-Square & P-Value \\
\hline Freq. & 99 & 50 & 20 & 10 & 13.56 & 0.001 \\
\hline
\end{tabular}

As we can see from the results of Table 8 P-value is statistically significance and we can reject the null hypothesis leading us to conclude that there is a meaningful difference among five different groups of problems. Our detailed survey indicates that organizational structure is the most important barriers on remote working.

\subsection{The fifth hypothesis}

The last hypothesis of this survey investigates whether remote working has improved quality of work or not. To examine this hypothesis we use Pearson correlation test and Table 9 summarizes the results of our survey.

The results of Table 9 indicate that all components of SERVQUAL questionnaire are statistically meaningful when the level of significance is one percent. In other words, people who participated in remote working believe they could improve the quality of their work. 
Table 9

The summary of Pearson correlation test

\begin{tabular}{lcccc}
\hline Dimension & Pearson correlation & Determinant coefficient & Adjusted Determinant coefficient & P-value \\
\hline Reliability & 0.186 & 0.034 & 0.41 & 0.001 \\
Physical aspects & -0.24 & 0.0496 & 0.0401 & 0.001 \\
Responsibility & 0.232 & 0.0538 & 0.458 & 0.001 \\
Empathy & 0.156 & 0.0245 & 0.018 & 0.001 \\
Assurance & 0.389 & 0.151 & 0.123 & 0.001 \\
Quality of service & 0.361 & 0.131 & 0.127 & 0.001 \\
\hline
\end{tabular}

We have also performed regression analysis to see how remote working could contribute on quality of the work. Table 10 demonstrates the results of ANOVA test on regression analysis.

Table 10

The summary of regression analysis

\begin{tabular}{llllll}
\hline & Sum of Squares & df & Mean of Squares & F & P-Value \\
\hline Regression & 5.123 & 1 & 5.123 & & \\
Residual & 363.96 & 205 & 1.78 & 2.87 & 0.011 \\
\hline Total & 215593.26 & 206 & & & \\
\hline
\end{tabular}

The result of ANOVA test indicates that F-value is statistically significance, which indicates there is a linear relationship between independent variable, remote work, and dependent variable, quality of work and Eq. (1) states the results of regression analysis,

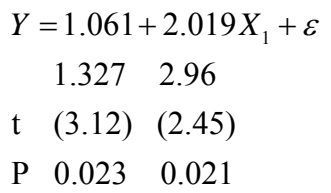

According to Eq. (1), an increase of one percent on remote working increases quality of work by 2.019. Both student values are statistically significance with $\alpha=0.05$. Therefore, we can conclude that both coefficients including intercept and slope have meaningful impacts on quality of work.

\section{Conclusion}

In this paper, we have studied the effect of remote working on quality of services in central office of Tehran municipality of Iran. The proposed study designed a standard questionnaire to survey remote working and using an existing standard SERVQUAL questionnaire measure the level of quality of work because of remote working. The survey indicated that women who participated in remote working program were satisfied from this program in terms of personal, social as well as organizational productivity. Remote workers were highly satisfied from financial advantage of this program. Managers were, however, highly satisfied from the results of their female's remote working. In our survey, remote contract workers were more satisfied than remote formal workers were. The surveyed people believed organizational structure was the most important challenge for remote working followed by economical, personal and social issues.

\section{Acknowledgment}

The authors would like to thank the employees of municipality of Tehran for cordially supporting accomplishment of this project. 


\section{References}

Bird, J. (1986). Remote working: How to keep in touch with staff. Data Processing, 28(2), 87-88.

Dowling, M. (2012). Enabling remote working: protecting the network. Network Security, 2012(3), 18-20.

Dujardin, S., Pirart, F., Brévers, F., Marique, A.-F., \& Teller, J. (2012). Home-to-work commuting, urban form and potential energy savings: A local scale approach to regional statistics. Transportation Research Part A: Policy and Practice, 46, 1054-1065.

Ghafur, S. (2002). Gender implications of space use in home-based work: evidences from slums in Bangladesh. Habitat International, 26(1), 33-50.

Hart, J. (2009). Remote working: managing the balancing act between network access and data security. Computer Fraud \& Security, 2009(11), 14-17.

Perugia, A., Moccia, L., Cordeau, J.F., \& Laporte, G. (2011). Designing a home-to-work bus service in a metropolitan area. Transportation Research Part B: Methodological, 45(10), 1710-1726

Tromp, D.M., \& Blomme, R.J. (2012). The effect of effort expenditure, job control and work-home arrangements on negative work-home interference in the hospitality industry. International Journal of Hospitality Management, 31(4), 1213-1221 